\section{Recovery of Caprinized and Lapinized Rinderpest Viruses from Condensed Water Vapour removed during Desiccation}

Stein and Rogers ${ }^{1}$ demonstrated the presence of Newcastle disease virus in the condensed water vapour removed during desiccation of material containing that virus. They failed to demonstrate the presence of vesicular stomatitis, equine encephalomyelitis, equine infectious anæmia and swine fever viruses under similar conditions.

The necessity arose for the desiccation of material containing virulent rinderpest virus in an Edwards's centrifugal freeze-dryer, normally used for desiccation of caprinized and lapinized rinderpest virus vaccines for field use. Possible contamination of the machine by virulent virus in the condensed water vapour was a factor which had to be considered. Caprinized and lapinized viruses were used to study the problem.

Spleen pulp, harvested from reacting goats, was processed in wide-mouthed tubes covered with singlelayer lint sterility caps. After ten hours processing, the refrigerated coils were permitted to warm up and the condensed water vapour was collected as it drained from the exhaust valve of the condenser chamber. $5 \mathrm{ml}$. of this condensate was inoculated subcutaneously into each of four susceptible bullocks. These animals showed typical caprinized virus reactions after four to five days. One animal died on the eleventh day due to intercurrent disease. Fourteen doys after inoculation the remaining animals were challenged with caprinized virus. They showed no reaction to the challenge dose whereas two susceptible controls reacted typically. The experiment was repeated with four more bullocks. Three gave typical thermal reactions while the remaining one was unaffected. On challenge, all four proved to be immune and three control animals responded thermally.

In both experiments the results indicated the presence of caprinized rinderpest virus in the condensate.

Similar results were obtained using lapinized rinderpest virus. Of six rabbits inoculated intravenously with $1 \mathrm{ml}$. of condensate, five showed the usual temperature rise within $60 \mathrm{hr}$.; the remaining one showed no reaction. Two of the reacting rabbits were killed after $96 \mathrm{hr}$. and were found to have typical lesions on post-mortem examination. After ten drys the remaining four rabbits were challenged with lapinized virus. Three showed no reaction, whereas the fourth responded with a mild rise in temperature. Two control animals reacted normally. The results show that lapinized virus was present in the condensed water vapour removed during desiccation.

This work has not been repeated with virulent rinderpest virus; but it seems most probable that it could be recovered in the same manner. The necessity for collecting the condensed water vapour into disinfectant and for disinfection of the machine are apparent. It is thought that the major part of the virus in the condensate is carried over during the period of evaporative freezing when dissolved gases and water vapour are removed rapidly as indicated by the rise of condenser temperature from $-45^{\circ} \mathrm{C}$. to the region of $-20^{\circ} \mathrm{C}$. or highe:. In this period approximately 20 per cent of the original water content is removed. Once frozen, desiccation of the material becomes considerably slower.
It has not proved possible to demonstrate the presence of either of the test viruses in material obtained by swabbing the walls of the desiccating chamber after processing.

\section{Veterinary Research Laboratory, \\ Vom, P.O. Bukuru, \\ Northern Nigeria. \\ ${ }^{1}$ Stein, C. D., and Rogers, H., Amer. J. Vet. Res., 11, 339 (1950). \\ Indirect Determination of Water Retention in Cattle as a means of estimating Energy Exchange}

THE starch equivalent or net energy system, which is the basis of livestock rationing in Great Britain, measures the nutritive value of feeds in terms of the body storage of energy which occurs when they are given to fattening cattle. Only a small number of respiration chambers and calorimeters are available for work with large animals, and the expense and labour involved in their operation limit the number of experiments which can be carried out. Consequently, published values ${ }^{1}$ are either the original ones of Kellner ${ }^{2}$ or crude estimates based on determinations of digestibility of the feed by sheep.

An attempt has therefore been made to determine indirectly the fat storage of cattle. Protein and ash retention may be estimated by the balance method. The remaining components of a gain of weight of an animal are fat and water, and thus an accurate determination of water retention would permit an estimate of the storage of body fat. The small amount of carbohydrate stored can be ignored. In our hands, water retention could not be accurately computed from determinations of total body water by the antipyrine dilution technique ${ }^{3}$ before and after a period of subsistence on a constant diet. Nevertheless, gross changes in the water content of the body over long periods could be estimated in this way, and the method may therefore be used for evaluating the composition of gains in body-weight of cattle at pasture.

A method has now been developed which permits the accurate estimation of water retention from the retention of sodium and potassium. Analysis of the tissues of foetal, young and mature cattle showed that their water content could be predicted from the equation

Water (gm.) $=0 \cdot 2922 \mathrm{Na}(\mathrm{mgm})+.0 \cdot 1471 \mathrm{~K}(\mathrm{mgm}$.$) .$

This equation was obtained by the method of least squares and applied to organs, tissue fluids and fat depots, varying in water content from 99 per cent (pericardial fluid) to less than 10 per cent (fat depots of mature animals). It also applied to the whole foetus aged three months, to amniotic fluid and to the ingesta of the rumen, small intestine and cæcum. It did not apply to the contents of the abomasum, presumably due to the high concentration of hydrogen ions. The same equation applied to the tissues of sheep and rabbits. The standard error of estimate of water content was \pm 2.0 per cent. Since the equation applied to the individual tissues, it must apply to the animal as a whole and to increments in the growth of the animal, in which water retention may be estimated from the simultaneous retention of sodium and potassium. 